\title{
HLA association with HTLV-1/2 infection in different populations of Argentina
}

\author{
Carolina Berini ${ }^{1 *}$, Maria E Eirin ${ }^{1}$, Richard Malan², Rogelio Espejo ${ }^{3}$, Cecilia Delfino ${ }^{1}$, Graciela Theiler ${ }^{4}$, Mirna Biglione $^{1}$ \\ From 15th International Conference on Human Retroviruses: HTLV and Related Viruses \\ Leuven and Gembloux, Belgium. 5-8 June 2011
}

\section{Introduction}

HLA class 1 alleles HLA-A*24,"26 and HLA-B*07,"61 were associated to susceptibility for HTLV-1 infection. While HLA-A*02 was associated to protection to HAM/ TSP, HLA-B*07 was associated to susceptibility for disease. Alleles HLA-A*02 and HLA-B*27,"40,"48 were described in aboriginal populations of Russia genetically related to Andean aborigines. This study analyzed the association of HLA with susceptibility to HTLV-1 or -2 infections.

\section{Materials and methods}

60 negative samples from aboriginal populations, 23 HTLV-1 samples (12 from blood donors (BD), 11 from Kollas) and 32 HTLV-2 positive samples from Buenos Aires residents were analyzed. HTLV-2 positive individuals and $\mathrm{BD}$ were predominantly of Caucasian origin. HLA class 1 (A, B) characterization was performed on genomic DNA using the PCR-SSO technique and chemiluminescence. Exons 2 and 3 of HLA-A and B genes were amplified.

\section{Results}

The HLA-A*02 allele was frequently observed in all groups, being significantly higher among HTLV-1+, and among HTLV-1+ Kollas compared to non-infected ones $(\mathrm{p}=0.03)$. HLA- $\mathrm{A}^{*} 31$ and "68 were significantly more frequent among negative individuals. HLA-B*07 was higher in HTLV-2+ individuals. HLA-B*35 was higher in HTLV-1 compared to HTLV-2 and in HTLV-1 infected Kollas compared to HTLV-1 infected Caucasians but similar to negative Kollas. HLA-B*40 was higher in negative individuals compared to HTLV-2+ ones.

\section{Discussion}

These data suggest a possible association of HLA-A*02 to susceptibility to infection while HLA-A*31 and "68 may have a possible protective effect against HTLV-1 natural infection. HLA-B*07 might increase HTLV-2 susceptibility to infection. These results show that the allele HLA-B*35 is associated to ethnic groups while the presence of alleles HLA-A*02 and HLA-B*07 may increase susceptibility to HTLV-1 and HTLV-2 infection, respectively. Our observations support that the HLA haplotype modulates the susceptibility to HTLV-1/ 2 infection.

\section{Author details \\ ${ }^{1}$ Centro Nacional de Referencia para el SIDA, Departamento de Microbiología, Facultad de Medicina, Universidad de Buenos Aires, Buenos Aires, Argentina. ${ }^{2}$ Banco de Sangre Central de la Provincia de Misiones, Misiones, Argentina. ${ }^{3}$ Hospital Rawson, Servicio Laboratorio Central, Sector Biología Molecular, San Juan, Argentina. ${ }^{4}$ Laboratorio de Inmunogenética, Hospital de Clínicas, Buenos Aires, Argentina.}

Published: 6 June 2011

doi:10.1186/1742-4690-8-S1-A107

Cite this article as: Berini et al:: HLA association with HTLV-1/2 infection in different populations of Argentina. Retrovirology 2011 8(Suppl 1):A107.

\footnotetext{
* Correspondence: cberini@fmed.uba.ar

${ }^{1}$ Centro Nacional de Referencia para el SIDA, Departamento de Microbiología, Facultad de Medicina, Universidad de Buenos Aires, Buenos Aires, Argentina

Full list of author information is available at the end of the article
}

(c) 2011 Berini et al; licensee BioMed Central Ltd. This is an open access article distributed under the terms of the Creative Commons 